\title{
DURABILITY OF A REPAIRED DUNE SAND MORTAR MODIFIED BY CERAMIC WASTE
}

\author{
Yacine ABADOU ${ }^{1 *}$, Ratiba KETTAB ${ }^{2}$, Abderrahmane GHRIEB ${ }^{3}$ \\ ${ }^{1}$ Civil Engineering Department, Polytechnic National School of Algiers, 16000 Algiers, Algeria \\ ${ }^{2}$ Laboratory of Construction and Environment, Polytechnic National School of Algiers, 16000 Algiers, Algeria \\ ${ }^{3}$ Civil Engineering Department University of Djelfa, 17000 Djelfa, Algeria
}

Received 21 October 2017; accepted 20 January 2018

\begin{abstract}
The waste-modified mortars have an important place in the range of repair products. The objective of this study is to better understand and analyze, in one hand, the influence of ceramic waste in the dune sand mortars on the quality of repair concrete surfaces, in the other hand, durability of the mortars in interaction with the substrates to which they are applied. As regards the mortar layer durability, two indicators are chosen: the first is the adhesion to the substrate, and the second is the stress state in the mortar layer. For this, two types of modified mortars were made using two types of waste ceramics: sanitary ceramics and earthenware. To evaluate the quality of the adhesion to a substrate surface to be repaired, an adhesion test based on the three point bending test was implemented, taking into account the influences of the environment, the state of the surface of the substrate, the nature of the substrate defined by its water saturation degree and its porosity. The mortar composition parameters, in particular, the nature and the amount of ceramic, were studied. The results enable us to evaluate the influences of the waste ceramic incorporation in the mortar and the substrate condition on which the mortar is applied. Show that the adhesion depends on both the type and the amount of the used ceramic waste and the applied cure. It is optimized from $30 \%$ of ceramic earthenware and sanitary mortar adhesive strengths are higher than mortars based on dune sand ones.
\end{abstract}

Keywords: dune sand, ceramic waste, repair mortar, adhesion, mechanical strength, durability.

\section{Introduction}

The majority of concrete structures are exposed to aggressive environments that contribute to increase the rate of concrete deterioration. Often, rehabilitation is necessary to extend the service life of these structures. In most cases, the structure is repaired by replacing the damaged concrete surface with a new layer of mortar. The source of deterioration and the mechanism of its development, corrosion of embedded reinforcement are recognised as the major problem affecting the durability of concrete structures.

The cost associated with these repairs represents great economic challenges for building owners who have to find solutions and optimized repair methods. These lead us to think about a new mortar to repair these damaged structures. The developed mortar in this study was based on dune sand with very high availability especially in southern Algeria because of the very low cost and the ceramic waste. The literature review concluded that, in general, the incorporation of ceramic waste significantly improves the material characteristics (durability, mechanical strength, modulus elasticity,..) (Farinha, de Brito, \& Veiga, 2015; Medina, Frías, Sánchez, \& de Rojas, 2012a; Pincha \& Arnon, 2010; Alves, Vieira, de Brito, \& Correia, 2014; Abadou, Mitiche-Kettab, \& Ghrieb, 2016).

Many authors (Bijen \& Salet, 1994; Fiebrich, 1994) studied the causes of non-adherence of a repairing mortar or bonding layer on a concrete substrate. They pointed out the interest of using polymeric binders in order to modify cement mortars and to promote and/or increase adherence. The polymer-modified mortars have an important place in the range of repair products. The research concluded that the adhesion depends on both the type and the amount of polymer used in addition to the mortar and the cure applied. It is optimized from $10 \%$ of polymer and EVA mortar adhesive strengths are higher than SA mortars ones (Tchetgnia, Marceau, \& Chaussadent, 2013).

${ }^{\star}$ Corresponding author. E-mail: abadouyacine@gmail.com 
An adequate choice of repair mortars is critical for the success of a restoration intervention. The mortar solution to be applied should be compatible with the ancient materials and durable (Silva, Ferreira Pinto, \& Gomes, 2015). The performance and durability of a repair mortar and its compatibility with the old materials is strongly influenced by its pore structure. Ceramic waste-based dune sand mortars have been increasingly used for this purpose in order to achieve the required compatibility with the repair modified mortar materials; they have an important place in the range of repair products. For this reason, several articles have been published on the virtues of using wastebased mortars for restoration.

The research on ceramic wastes as partial substitute for fine aggregates or cement has not been overly exploited as the other areas.

Recent studies carried out in the field of repair mortars have encouraged the use of dune sand mortars based on ceramic waste for restoration purposes or rehabilitation structure. Research on recycled ceramic waste conducted with focus on investigating whether ceramic wall tile wastes used as partial substitute for cement and fine aggregates could prove to be beneficial since the two materials are the most high-priced during concrete production (Zimbili, Salim, \& Ndambuki, 2014; Gomes \& de Brito, 2009; López, Llamas, Juan, Morán, \& Guerra, 2007).

Silva, de Brito, and Veiga (2010) investigated on the red-clay ceramic waste construction in mortar production and concluded that replacement ratios of up to $20-50 \%$ improved the adhesive strength relative when compared with a reference mortar. The incorporation of red-brick powder in mortar generally improved its performance when compared with a reference mortar (Silva et al., 2010; Silva, de Brito, \& Veiga, 2009).

Medina, Sánchez de Rojas, and Frías (2012b) conducted research on the mechanical behaviour of concretes using ceramic waste. In their research, they incorporated ceramic wastes of sanitary. They discovered that recycled ceramic aggregates showed a more irregular shape than NA, which provides a higher bond between recycled ceramic aggregates and the cement paste.

Reference Farinha et al. (2015) researched and confirmed the possibility of usage of fine sanitary ceramic waste in partial substitution of $10 \%, 15 \%$ and $20 \%$ in the production of mortar. Furthermore, they obtained positive results of the modified mortar with $20 \%$ addition of GSWF; it was the one with the best performance of all the modified mortars, with increase in adhesion strength.

To evaluate the performance of the mortars with sanitary ware waste, a wide experimental campaign was developed. Four replacement ratios were tested $(0 \%, 20 \%$, $50 \%$ and $100 \%$ ) of sand by aggregates from crushing sanitary ware waste. Study results (Lucas, de Brito, Veiga, \& Farinha, 2016) have shown, that strength of concrete containing from $50 \%$ of aggregate of ceramic sanitary ware waste was higher by $6-17 \%$ than that of mortar without this admixture. The adherence to the substrate was evalu- ated at 28 days (before ageing) and after ageing. The adhesion strength at both ages was higher for mortar SWM50 by $6 \%$ and $17 \%$, respectively before and after ageing. The adhesion strength improved after accelerated ageing tests, in the mortar with $50 \%$ replacement of sand by sanitary ware waste.

According to Matias, Faria, and Torres (2014) several test and seven ceramic waste products collected were analysed in their study in order to produce mortars intended to repair and replace the old ones. They have studied the performance of air lime mortar made with ceramic waste and attempted to improve the different properties by using ceramic waste. It was found that the waste could improve not only mechanical strength but also effect pozzolanic.

Jiménez, Ayuso, López, Fernández, and de Brito (2013) used fine recycled aggregate from ceramic partition wall rubble waste in mortar production. They concluded that replacement ratios of up to $40 \%$ improved that replacement ratios of up to $40 \%$ by volume did not significantly affect the properties of fresh and hardened mortar, with the exception of density and workability. The adhesive strength of hardened mortar was not affected by the replacement ratio. One of the critical improving the durability of concrete repairs and overlays is lasting and sufficient interfacial bond between repair material and existing concrete substrate.

Adhesion is defined as adherence of two materials in contact or in more colloquial way of being stuck together. It is not surprising that adhesion is the fundamental issue in construction engineering. The adhesion strength of concrete repair mortar is one of the most important technical characteristics of the repair materials (Czarnecki, 2008; Guangiing, Jinwei, \& Gengying, 2002). Adhesion is the set of physico-chemical phenomena that are responsible for the formation and cohesion of the interfaces between two bodies (Darque-Ceretti \& Felder, 2003).

In the field of mortars applied on a substrate, adhesion is linked to several factors:

- Adhesiveness which is the ability to create forces of interactions between the substrate and the mortar,

- The surface condition and nature of the substrate (porosity, roughness, absorptivity, cleanliness),

- The ability of the mortar to create contact with the substrate to which it is applied.

Adhesion of a concrete repair to an existing substrate is a complex phenomenon that involves different types of bond: chemical bond (chemical reaction between the substrate and the repair material), mechanical bond (associated with the interpenetration of the repair material into the roughness and porosity of the substrate, resulting in mechanical anchorage) and physical bond (related to the van der Waals and surface tension forces) (Courard, 2000). The term "adhesion" describes the condition in the boundary layer between two connecting materials with a common interface. Adhesion mechanisms can be divided basically into mechanical interaction, thermodynamic mechanisms, and chemical bonding, Adhesion and 
cohesion are two interconnected parts of the process of forming the contact zone. However, the most important component of bond strength for concrete repair is the adhesion.

The waste-modified mortars have an important place in the range of repair products. This study concerns the reuse and the valorization of ceramic waste materials. The main objective consists in the use of aggregates issued from the dune sand mortar for making a new manufactured one, and

the studies the influence of the presence of ceramic waste in these dune sand mortars on the quality of repair concrete surfaces, including their adhesion properties. Two types of modified mortars were made using two ceramic waste white and red.

The experimental work presented in this paper is part of the overall development program of local materials conducted by the structure rehabilitation and materials laboratory:

it is based on the following elements:

- the Effect of the ceramic waste incorporation on physical and mechanical characteristics of dune sand mortar.

- the Evaluation of adhesion characteristics of the repair mortar substrate.

\section{Experimental method}

\subsection{Materials}

The materials used in the experimental programme were: cement, dune sand, grinded sanitary and earthenware "floor and wall tile" ware waste. The cement used is a Portland cement CEM II/A 42.5, (conforming to EN 1971:2000). The sand used is dune sand (southern Algeria), the granulometric range is between 0.08 and $0.5 \mathrm{~mm}$ and 1.10 fineness modulus. The recycled ceramic aggregate employed came from a ceramic sanitary and earthenware ware factory. This ceramic waste was subjected to a crushing process using a jaw crusher, the granulometric range is between 0.08 and $2.0 \mathrm{~mm}$ and 2.120, 1.967 fineness modulus respectively. The measured density of ceramic sanitary and earthenware "floor and wall tile" $(2.23 ; 1.23)$

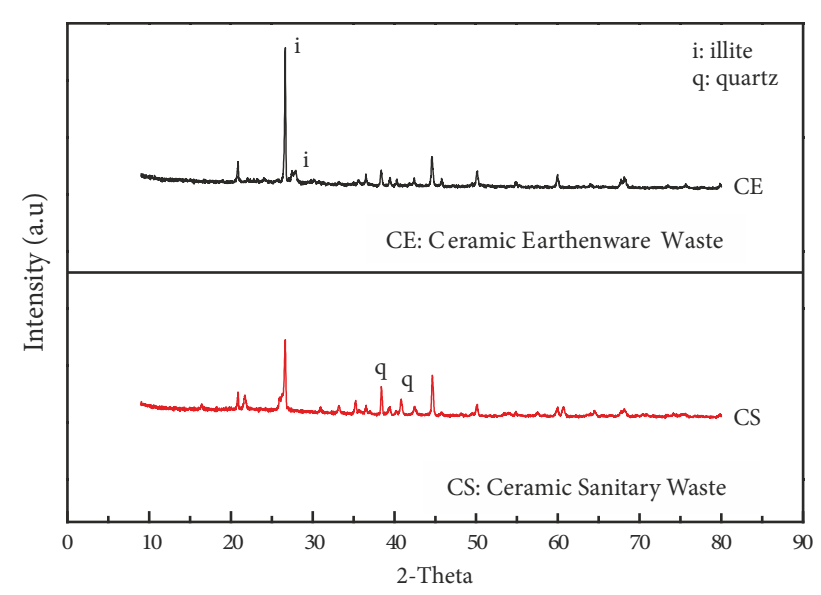

Figure 1. X-ray diffraction of materials

was found to be similar to the one of ceramic sanitary additives used in concrete by Medina et al. (2012b) and Halicka, Ogrodnik, and Zegardło (2013). According to the XRD analysis shown in Figure 1, the principal crystalline components found in the ceramic waste were quartz $(\mathrm{Q})$ and illite (I).

In the present research, seven mixtures were produced to evaluate the influence of waste sanitary and earthenware ceramic on mortar properties. Table 1 presents the composition of the materials used: a reference mortar based on dune sand formulated in accordance with EN 196-1:2005 $\left(M_{D}\right)$ and three mortars containing respectively 10, 30 and $50 \%$ of ceramic waste by weight of sand in replacement of natural aggregates $\left(M_{S 10 \%}, M_{S 30 \%}, M_{S 50 \%}, M_{E 10 \%}, M_{\mathrm{E} 30 \%}\right.$ and $\left.M_{E 50 \%}\right)$. Mortars mixes as well as $4 \times 4 \times 16 \mathrm{~cm}$ prisms ( 3 for every batch) were prepared in accordance with European Standard EN 196-1:2005.

\subsection{Methodology}

\subsubsection{Bond strength evaluation}

In different test series conducted to evaluate the effect of selected parameter upon repair bond, repaired test concrete were characterized exhaustively for bond strength using pull-off test, in some cases torsional bond test.

Table 1. Composition of designed mortars

\begin{tabular}{|c|c|c|c|c|c|c|}
\hline \multirow{3}{*}{\multicolumn{2}{|c|}{ Type and symbol of mortar }} & \multirow{3}{*}{ Cement } & \multicolumn{4}{|c|}{ Mortar composition (g) } \\
\hline & & & \multirow{2}{*}{ dune sand } & \multicolumn{2}{|c|}{ ceramic } & \multirow{2}{*}{$\mathrm{W} / \mathrm{C}$} \\
\hline & & & & sanitary & earthenware & \\
\hline Reference mortar & $\mathrm{M}_{\mathrm{D}}$ & 450 & 1350 & 0.00 & 0.00 & 0.70 \\
\hline Mortar with ceramic sanitary & $M_{S 10 \%}$ & 450 & 1215 & 0135 & 0.00 & 0.70 \\
\hline Mortar with ceramic sanitary & $M_{S 30 \%}$ & 450 & 1080 & 0270 & 0.00 & 0.70 \\
\hline Mortar with ceramic sanitary & $M_{S 50 \%}$ & 450 & 0945 & 0405 & 0.00 & 0.70 \\
\hline Mortar with ceramic earthenware & $M_{E 10 \%}$ & 450 & 1215 & 0.00 & 0135 & 0.75 \\
\hline Mortar with ceramic earthenware & $M_{E 30 \%}$ & 450 & 1080 & 0.00 & 0270 & 0.75 \\
\hline Mortar with ceramic earthenware & $M_{E 50 \%}$ & 450 & 0945 & 0.00 & 0405 & 0.75 \\
\hline
\end{tabular}


Another method of measuring the adhesion is used regularly splitting; the test is intended for the analysis of concrete, the used pieces are size $16 \times 32 \mathrm{~cm}$. A third technique that is frequently used is shear measurement, the difficulty lies in the manufacture of substrates to obtain the desired inclination angle. To overcome all these drawbacks, we chose to use a flexure three-point test to qualify and quantify the adhesion. Adhesion between the repair material and the concrete substrate is a very important technical property towards structural and non-structural repair as well. Proper level of adhesion assures utmost load capacity of the repaired system. The adhesion test flexure 3 points, as described in EN 1015-12, permits to determine the bond strength between mortar and substrate. The major reasons that guide this choice are: the first is to facilitate the use of these techniques with mastered apparatus, the second is the possibility to exploit the results in parallel with the intrinsic properties of the substrate ( $\operatorname{mortar} M_{D}$ ).

\subsubsection{The studied parameters}

Several factors are involved in the bonding of the two materials (Courard, 1998). Our work has focused on three factors which are described below:

1 . The influence of the ceramics waste types used in the modified mortars: To know the effect of this component on the mortars adhesion.

2. The State of substrate surface: to study the impact of the roughness and wetting the substrates surface on adhesion. The tests were carried out with two types of surface roughness of the repaired mortar.

- Dry and rough surface (DR): The half-specimen with rough surface shown in Figure $2 \mathrm{a}$ was obtained by fracturing the specimens $4 \times 4 \times 16 \mathrm{~cm}^{3}$ by three-point bending

- Dry and rough surface oblique (DRO): The halfspecimen with rough surface was obtained by fracturing the specimens $4 \times 4 \times 16 \mathrm{~cm}^{3}$ by threepoint bending, this surface is considered as treated surface (Figure $2 \mathrm{~b}$ ). There are several methods to prepare the surface, and it is quite important to choose the best way since it has a decisive influence on bond in the interface (The surface is prepared with pneumatic chipping hammers). The overall geometry of the surface should be simple with no re-entrant corners.

- Rough surface and saturated with water (SR): The half-specimen surface saturated with water shown in Figure $2 \mathrm{c}$ was obtained by fracturing the specimens $(4 \times 4 \times 16) \mathrm{cm}^{3}$ by three-point bending and the immersion of the half-specimen during the 24 hours preceding the manufacture of bi-component specimen.

- Rough and oblique surface saturated with water (SRO): The half-specimen surface saturated with water shown in Figure 2d, was obtained by fracturing the specimens $(4 \times 4 \times 16) \mathrm{cm}^{3}$ by three-point bending and the immersion of the half- specimen during the $24 \mathrm{~h}$ preceding the manufacture of bi-com-
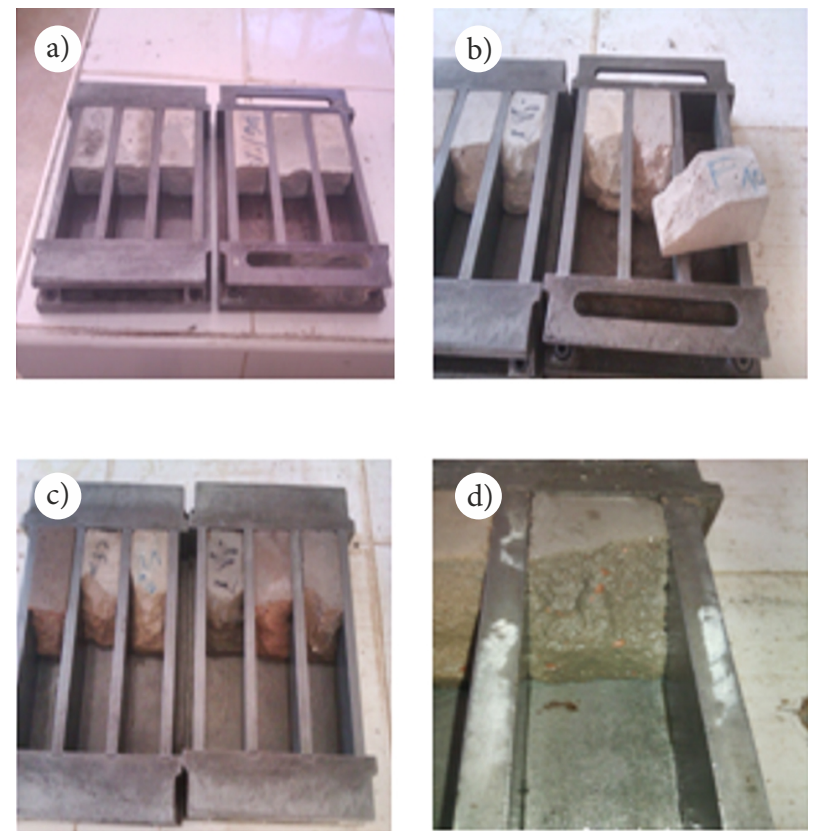

Figure 2. The half-specimen surface saturated with water: a - Dry and rough surface (DR); b - Wet and rough oblique surface (DRO); c - Wet and rough surface (SR); $\mathrm{d}-$ Wet and rough oblique surface (SRO)

ponent specimen. The geometric surface area and the contact surface area, were prepared with pneumatic chipping hammers to obtain oblique surface.

3. Environment substrate / repair system: Samples after $24 \mathrm{~h}$ were removed from the mold sand stored for one month before the test in the three curing conditions (immersion in water, in the open air and hot environment (storage in an oven under temperature $\left.50{ }^{\circ} \mathrm{C}\right)$.

\subsubsection{Preparation of specimens}

Specimens used for adhesion tests are called bi-component. Their dimensions are the same as those used for mechanical testing $(4 \times 4 \times 16) \mathrm{cm}^{3}$ but they are composed of two different parts to simulate a repair system:

- A substrate part that represents the part of the system to be repaired. It is a half test piece $(4 \times 4 \times 16) \mathrm{cm}^{3}$ obtained by fracture flexion of the initial specimen made with the mortar $M_{d}$ (reference mortar or dune sand mortar), according to the surface state sought; a substrate part which is the part of the system for repair. It must have been manufactured at least 28 days before use and not have been treated during this period. It is thus stored in the laboratory environment before use.

- Figure 3 shows the other half specimens are the part repair product made with mortar to study. It is poured directly into the mold $(4 \times 4 \times 16) \mathrm{cm}^{3}$ after the substrate part has been positioned there. The mortar pouring the steps are the same as those used for the manufacture of test specimens summarizes the steps for manufacturing the bi-component specimens. 

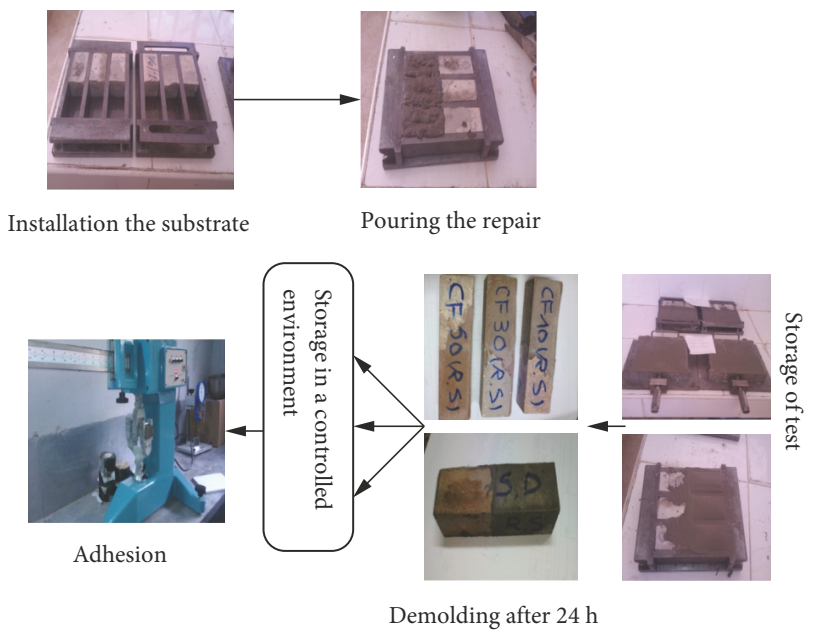

Figure 3. The manufacturing steps of the specimens

\section{Results and discussion}

\subsection{Properties of hardened mortars}

The mechanical properties of the mortars were tested in laboratory; flexural and compressive strength test results recorded for the different tested mortars are summarized in Table 2 depending on the type of the applied curing. Incorporation of ceramic waste aggregates led to a systematic improvement of the mechanical properties; the benefits increased with the addition rate. At $28 \mathrm{~d}$, the use of ceramic aggregates resulted an increase in flexural strength (up to 37\%) and compressive strength (up to 150\%) (Abadou et al., 2016).

Many researchers have been conducted worldwide on the usage of ceramic wastes as an additive in structural and non-structural concrete. The improvement of physicomechanical properties and workability of mortars by adding various red and white waste of ceramic were also studied in detail. Positive results were obtained from these studies. Therefore in terms of mechanical performance, there were considerable improvements, highlighting the potential of using the sanitary ware as aggregates.

\subsection{Influence of ceramic waste and surface state of water saturation in different storage conditions on adhesion}

After $28 \mathrm{~d}$, the adhesion stresses were measured, the results are shown in Figure 4:

The exposition of modified mortar on a high temperature has a negative impact on the mortar adherence. Moreover, the failure is purely adhesive (A) because a part of water is evaporated under these conditions, the fact that limits the cement hydrate. The water immersion augments the modified mortar adherence. This result is predicted as well because water is available for all cement hydrate. Furthermore, the cohesive failure can be found in the substrate or in the preparation of the mortars. However, the flexion resistance of mortar referencing $M_{D}$ is not always reached.

In addition to that, the high temperature reduces the adherence when the water immersion increases. This result is confirmed through the fact that the majority of failures are, in one hand, cohesive in the substrate or on the mortar preparation with water immersion, in the other hand, adhesive when the samples are in the curing environment and under $50{ }^{\circ} \mathrm{C}$.

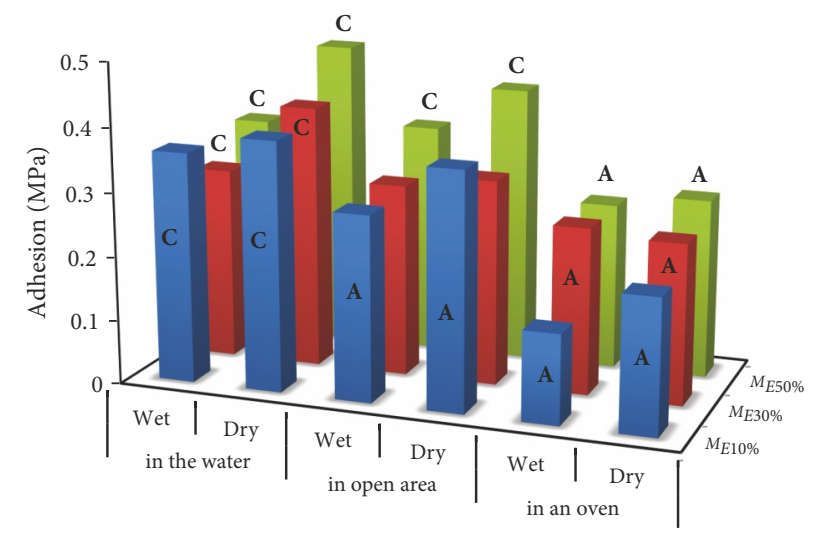

Figure 4. Evolution of the bond stress during $28 \mathrm{~d}$ of storage in different environments with water saturation of the substrate: Mortar with earthenware ceramic waste

Table 2. Properties of mechanical mortars made in laboratory and have undergone different cures

\begin{tabular}{|c|c|c|c|c|c|c|c|}
\hline \multirow{3}{*}{\multicolumn{2}{|c|}{$\begin{array}{c}\text { Ceramic waste (\%) } \\
\text { C/S }\end{array}$}} & \multicolumn{3}{|c|}{ Compressive strength (MPa) } & \multicolumn{3}{|c|}{ Flexural strength $(\mathrm{MPa})$} \\
\hline & & \multicolumn{3}{|c|}{ Storage } & \multicolumn{3}{|c|}{ Storage } \\
\hline & & in the water & in open air & in an oven & in the water & in open air & in an oven \\
\hline \multirow[t]{2}{*}{$M_{D}$} & 00 & 8.52 & 11.14 & 7.60 & 0.648 & 0.565 & 0.607 \\
\hline & 10 & 11.05 & 6.68 & 6.55 & 0.706 & 0.592 & 0.470 \\
\hline \multirow[t]{3}{*}{$M_{S \%}$} & 30 & 18.81 & 15.00 & 14.87 & 0.779 & 0.759 & 0.513 \\
\hline & 50 & 22.28 & 18.35 & 15.07 & 0.893 & 0.774 & 0.660 \\
\hline & 10 & 9.65 & 7.27 & 6.23 & 0.719 & 0.501 & 0.453 \\
\hline \multirow[t]{2}{*}{$M_{E \%}$} & 30 & 16.22 & 10.28 & 9.50 & 0.696 & 0.744 & 0.486 \\
\hline & 50 & 17.33 & 17.23 & 19.20 & 0.839 & 0.774 & 0.660 \\
\hline
\end{tabular}


In Figure 4 and Figure 5 we can observe that water saturation in prepared substrate cause a hard reduction of mortars adherence whatever the waste is earthenware ceramic or sanitary one; moreover, the adherence on surface with water saturation does not depend practically on the ceramic wastes quantity. We note, in addition, that adherence progresses differently from the dry rough surface to the rough surface with saturation water; on dry surface, adherence reaches its maximum (50\%) with ceramic wastes; whereas, it is weak on surface with water saturation.

In short, this study concluded that modified mortars with incorporation of ceramic waste materials show that adhesion strength is higher in the modified mortar with incorporation up to $10 \%$ ceramic waste, than in the reference dune sand mortar. This is probably because the fine ceramic waste mixed with the mixing water penetrated the capillary pores of the substrate and formed a stronger interface. Then, the cement hydration will decrease the voids of the mortar making it more compact and thus more resistant (Farinha et al., 2015).

The adhesion strength was higher for mortar with replacement ratios up to $50 \%$ by $6 \%$ and $17 \%$, respectively before and after ageing. This increase is probably due to a delayed hydration of cement occurred during the humidity-ice cycles (Lucas et al., 2016).

Fernandez et al. (Ledesma, Jimenez, Ayuso, Fernandez, \& de Brito, 2015) stated that No statistically significant difference was observed for replacement ratios below $75 \%$, due to the dispersion of results in the pull off test. Although, the mean values for adhesive strength linearly decreased as the amount of RMA increased. Whereas Jiménez et al. (2013), found no statistically significant differences for replacement ratios up to $40 \%$. Comparing the results of our study with those of Corinaldesi and Moriconi (2009), Corinaldesi, Giuggiolini, and Moriconi (2002), they all found higher mortar-brick bond strength than the reference mortar. The results mention that water presents two opposite influences on the adherence as Julio, Branco, and Silva (2004) sees:

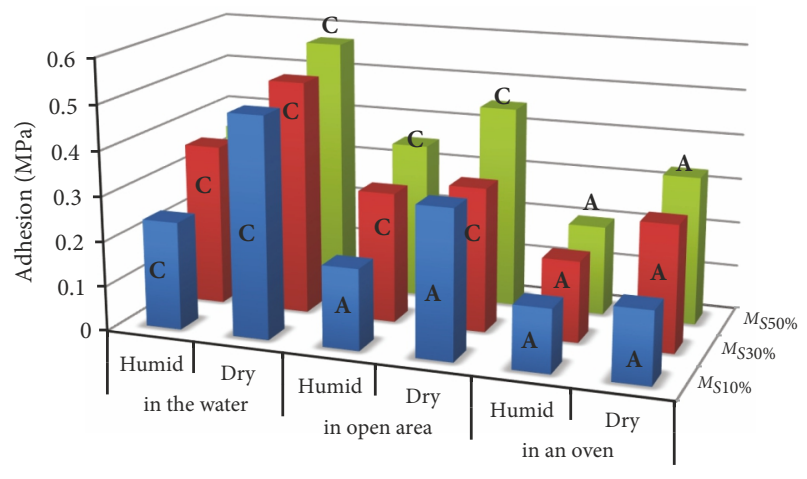

Figure 5. Evlution of the bond stress during $28 \mathrm{~d}$ of storage in different environments with water saturation of the substrate: mortar with sanitary ceramic waste
Surface water of the substrate augments the rapport (relationship) E/C on the mortar interface. The mortar display of the preparation becomes too easy, the fact that aids the contact with the surface of the substrate. When the water remains on the mortar interface/substrate, the contact between the two materials is limited and the local porosity can be increased.

\subsection{Influence of the roughness and failure mode on the mortar adhesion}

The influence of roughness surface of the substrate was also studied by pouring mortar modified with 10\%, 30\% and $50 \% \mathrm{CS}$, CE over a rough surface and an oblique rough surface. The tests were carried out on specimens having undergone an ambient curing in $28 \mathrm{~d}$.

We can observe in Figure 6 that the adhesion is higher when the mortar is cast onto a rough oblique surface then the rough surface. This is due to the fact that, for the same section serving, the contact surface between the two materials is more important on a rough sample than on the non-rough (Courard, 1998). Increasing surface roughness augments the contact surface (Julio et al., 2004; Momayez, Ehsani, Ramezaniapour, \& Rajaie, 2005) which promote adhesion.

In the modified mortars, there is an increase in adhesion over incorporation ratio, which approaches the flexural strength of the reference mortar. This progression shown in Figure7 $(\mathrm{a}, \mathrm{b})$ is also visible at the failure mode changes from a cohesive in the substrate and adhesive in the mortar where $10 \%$ ratio substitutions of ceramic waste and rough surface, changes strictly to a cohesive failures at the mortar with $30 \%$ and $50 \%$ substitution ratio and rough oblique surface. Noting that the adhesion mortar with ceramic sanitary waste $M_{S \%}$ is higher than the mortar with ceramic earthenware waste $M_{E \%}$ and the last one is higher than the reference dune sand mortar.

The results of these tests were also statistically analyzed with JMP 10.0 software, with a statistical function bivariate ANOVA.

A one-way ANOVA was carried out to determinate whether the mortar type factor in roughness surface had a statistically significant effect on adhesive strength. The $\mathrm{p}$-value of the F-test was less than 0.05 ( $\mathrm{p}$-value $=0.0131$ ),

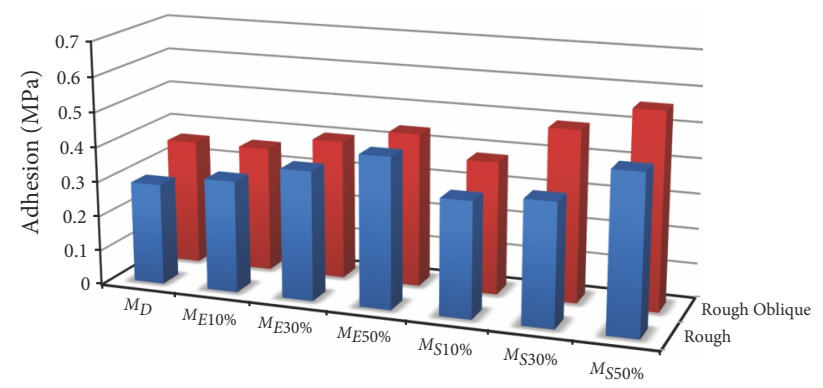

Figure 6. Influence of the roughness and failure mode on the mortar adhesion 
a)

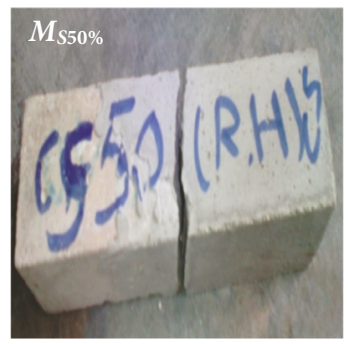

Cohesive in the substrate

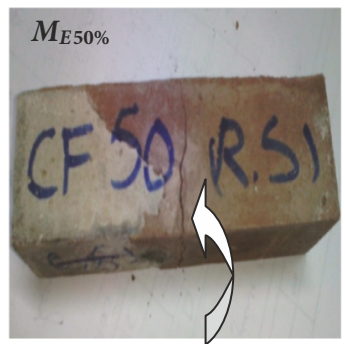

Cohesive in the repair

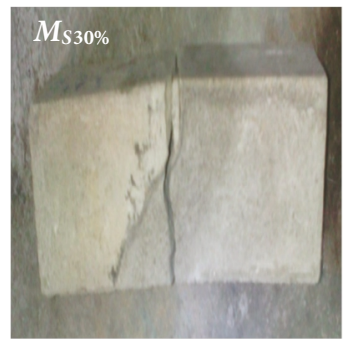

Cohesive in the substrate

b)

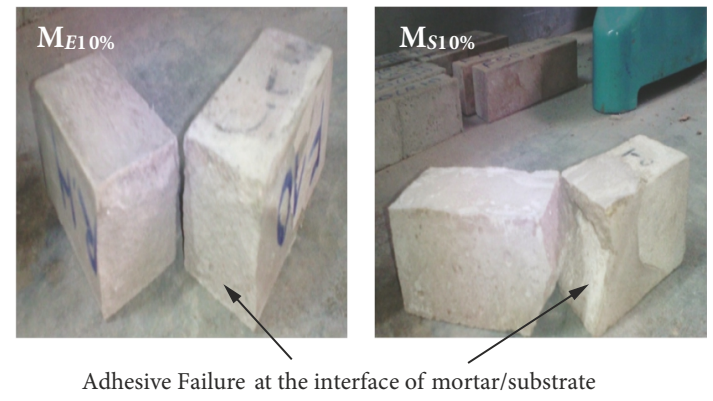

Figure 7. Failure mode on the mortar

Table 3. Multiple Range Test for rough oblique surface adhesive strength of hardened mortar by mortar type. Method: 95\% LSD

\begin{tabular}{|c|c|c|c|c|}
\hline Mortar & Count & $\begin{array}{c}\text { LS mean } \\
(\mathrm{MPa})\end{array}$ & $\begin{array}{c}\mathrm{SD} \\
(\mathrm{MPa})\end{array}$ & Homogeneous groups \\
\hline $\mathrm{A}\left(M_{D}\right)$ & 3 & 0.59 & 0.007 & $x$ \\
\hline $\mathrm{B}\left(M_{E 10 \%}\right)$ & 3 & 0.61 & 0.007 & $x$ \\
\hline $\mathrm{C}\left(M_{E 30 \%}\right)$ & 3 & 0.72 & 0.014 & $x$ \\
\hline $\mathrm{D}\left(M_{E 50 \%}\right)$ & 3 & 1.06 & 0.049 & $x$ \\
\hline $\mathrm{E}\left(M_{S 10 \%}\right)$ & 3 & 0.62 & 0.007 & $x$ \\
\hline $\mathrm{F}\left(M_{S 30 \%}\right)$ & 3 & 1.05 & 0.049 & $x$ \\
\hline $\mathrm{G}\left(M_{S 50 \%}\right)$ & 3 & 1.15 & 0.049 & $x$ \\
\hline
\end{tabular}

there was statistically significant difference between the mean of the adhesive strength of hardened mortar from one level of replacement to another at the $95.0 \%$ confidence level. A multiple range test was carried out to identify the significant differences between the mean values. The results are presented in Table 3 (two homogeneous groups with significant differences in the mean values of the adhesive strength). Figure 8 shows the range of means of the adhesive strength due to adhesion test flexure three points action with roughness surface for the all mortar types. The LSD range for mortar types without significant differences between means values overlapped.

\section{Conclusions}

In conclusion, the results demonstrated the advantages of incorporating ceramic waste sanitary and earthenware in dune sand mortars. In terms of mechanical performance,

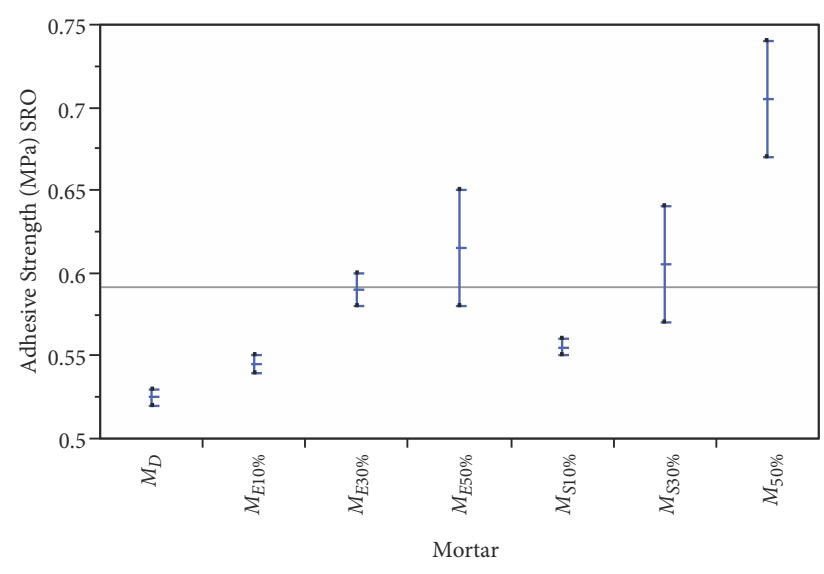

Figure 8. LSD range of the mean adhesive strength of hardened mortar for the seven mortar types tested with various replacement levels

there were considerable improvements, highlighting the potential of use of the ceramic waste as aggregates. The analysis of the values of all the properties tested for the mortar with a $10 \%, 30 \%$ and $50 \%$ replacement of dune sand, shows that the incorporation of white ceramic sanitary waste recycled in dune sand mortars causes a general improvement of its performance as compared with the one of a conventional mortar.

Based on this experimental investigation, it is feasible to use SC and CE as a dune sand replacement ratio material to produce mortar with acceptable performance. The following conclusions can be drawn:

1. The compressive strength shows that the use of $30 \%$ and $50 \%$ of ceramic waste increases the compressive 
strength and flexural strength by about $150 \%, 37 \%$ respectively.

2. The adhesive strength increases with the incorporation of ceramic waste, this is another property that is clearly improved in the present study. The incorporation of $30 \%$ and $50 \%$ of ceramic waste sanitary and earthenware instead of dune sand improved the adhesive strength around 55\%, 48\% respectively as compared with the reference mortar.

3. The adhesive strength of hardened mortar was affected by the replacement ratio. In the substrate adhesive strength tests the modified mortar behaved better than the reference mortar:

- By inclusion of ceramic waste into dune sand mortar, proper effective utilization of ceramic waste can be achieved to avail the quality of dune sand for the future generation.

- A clean, rough and dry surface before repair permits to ameliorate the adherence between the support and the modified mortar repair. The adherence strength at dry surface in different curing environment was higher for mortar $M_{S 50 \%}, M_{E 50 \%}$ above $30 \%$ and $20 \%$, respectively before and after ageing.

4. When the water remains on the mortar interface/ substrate the contact between the two materials are limited and the local porosity can be increased.

5. Roughness augmentation of a surface leads to surface contact augmentation. The roughness of the surface, affecting the wet ability of the support through the contact angle and the specific surface.

6. The highest bond strength and cohesive failure in the substrate or repair mortar are obtained mainly in the water emersion, dry rough surface and 50\% substitution ratio.

7. Statistical analysis determined better behaviour of mortar with ceramic waste in terms of adhesive strength for the roughness surface.

8. The highest bond strength and cohesive failure in the substrate or repair mortar are obtained mainly in the water immersion, dry rough surface and 50\% substitution ratio.

The analysis of the values of all the properties tested for the mortar with a ratio replacement of waste, shows that the incorporation of red-white recycled waste in dune sand mortars causes a general improvement of its performance as compared with the one of a conventional mortar, Thus, the choice of using ceramic waste to produce dune sand mortars it also has benefits from an economical, environmental, and technical advantages point of view and offers a possibility for improving the durability of mortars.

\section{References}

Alves, A. V., Vieira, T. F., de Brito, J., \& Correia, J. R. (2014). Mechanical properties of structural concrete with fine recycled ceramic aggregates. Construction and Building Materials, 64, 103-113. https://doi.org/10.1016/j.conbuildmat.2014.04.037
Abadou, Y., Mitiche-Kettab, R., \& Ghrieb, A. (2016). Ceramic waste influence on dune sand mortar performance. Construction and Building Materials, 125, 703-713.

https://doi.org/10.1016/j.conbuildmat.2016.08.083

Bijen, J., \& Salet, T. (1994). Adherence of young concrete to old concrete developement of tools in civil engineering, in Adherence of young and old concrete. Proceedings of $2 \mathrm{nd} \mathrm{Bo-}$ lomey Workshop (pp.1-24). Unterengstringen.

Czarnecki, L. (2008). Adhesion - a challenge for concrete repair concrete repair. 2nd International conference on concrete repair, rehabilitation and retrofitting (ICCRRR) (pp. 95-940). Cape Town, South Africa. https://doi.org/10.1201/9781439828403.sec11

Courard, L. (2000). Parametric study for the creation of the interface between concrete and repair products. Materials and Structures, 33, 65-72. https://doi.org/10.1007/BF02481698

Courard, L. (1998). Contribution to the analysis of parameters influencing the creation of the interface between concrete and repair systems. University of Liège.

Corinaldesi, V., \& Moriconi, G. (2009). Behaviour of cementitious mortars containing different kinds of recycled aggregate. Construction and Building Materials, 23, 289-294. https://doi.org/10.1016/j.conbuildmat.2007.12.006

Corinaldesi, V., Giuggiolini, M., \& Moriconi, G. (2002). Use of rubble from building demolition in mortars. Waste Management, 22, 893-899. https://doi.org/10.1016/S0956-053X(02)00087-9

Darque-Ceretti, E., \& Felder, E. (2003). Adhésion et adhérence (388 p.). CNRS édition, Sciences et Technique de l'ingénieur. ISBN 2271060923.

EN 197-1:2000. Cement. Part 1: composition, specifications and conformity criteria for common cements.

EN 196-1:2005. Methods of testing cement - Part 1: Determination of strength; 2005.

EN 1015-12. Methods of test for mortar for masonry - Part 12: Determination of adhesive strength of hardened rendering and plastering mortars on substrates. European Committee for Standardization (CEN); February 2000.

Farinha, C., de Brito, J., \& Veiga, J. R. (2015). Incorporation of fine sanitary ware aggregates in coating mortars. Construction and Building Materials, 83, 194-206.

https://doi.org/10.1016/j.conbuildmat.2015.03.028

Fiebrich, M. H. (1994). Scientific aspects of adhesion phenomena in the interface mineral substrate-polymers, in Adherence of young and old concrete. Proceedings of 2 nd Bolomey Workshop (pp. 25-58). Unterengstringen.

Guangiing, X., Jinwei, L., \& Gengying, L. (2002). A way for improving interfacial transition zone between concrete substrate and repair materials. Cement and concrete Research, 32, 18771881. https://doi.org/10.1016/S0008-8846(02)00840-2

Gomes, M., \& de Brito, J. (2009). Structural concrete with incorporation of coarse recycled concrete and ceramic aggregates: durability performance. Materials and Structures, 42, 663-675. https://doi.org/10.1617/s11527-008-9411-9

Halicka, A., Ogrodnik, P., \& Zegardło, B. (2013). Using ceramic sanitary ware waste as concrete aggregate. Construction and Building Materials, 48, 295-305. https://doi.org/10.1016/j.conbuildmat.2013.06.063

Jiménez, J. R., Ayuso, J., López, M., Fernández, J. M., \& de Brito, J. (2013). Use of fine recycled aggregates from ceramic waste in masonry mortar manufacturing. Construction and Building Materials, 40, 679-690. https://doi.org/10.1016/j.conbuildmat.2012.11.036 
Julio, E. N. B. S., Branco, F. A. B., \& Silva, V. D. (2004). Concreteto-concrete bond strength. Influence of the roughness of the substrate surface. Construction and Building Materials, 18(9), 675-681. https://doi.org/10.1016/j.conbuildmat.2004.04.023

López, V., Llamas, B., Juan, A., Morán, J. M., \& Guerra, I. (2007). Eco-efficient concretes: impact of the use of white ceramic powder on the mechanical properties of concrete. Bio systems Engineering, 96, 559-564.

https://doi.org/10.1016/j.biosystemseng.2007.01.004

Lucas, J., de Brito, J., Veiga, R., \& Farinha, C. (2016). The effect of using sanitary ware as aggregates on rendering mortars performance. Materials and Design, 91, 155-164. https://doi.org/10.1016/j.matdes.2015.11.086

Ledesma, E. F., Jimenez, J. R., Ayuso, J., Fernandez, J. M., \& de Brito, J. (2015). Maximum feasible use of recycled sand from construction and demolition waste for eco-mortar production e Part-I: ceramic masonry waste. Journal of Cleaner Production, 87, 692-706. https://doi.org/10.1016/j.jclepro.2014.10.084

Medina, C., Frías, M., Sánchez, M. I., \& de Rojas, M. I. (2012a). Microstructure and properties of recycled concretes using ceramic sanitary ware industry waste as coarse aggregate. Construction and Building Materials, 31, 112-118. https://doi.org/10.1016/j.conbuildmat.2011.12.075

Medina, C., Sánchez de Rojas, M. I., \& Frías, M. (2012b). Reuse of sanitary ceramic wastes as coarse aggregate in eco-efficient concretes. Cement and Concrete Composites, 34, 48-54. https://doi.org/10.1016/j.cemconcomp.2011.08.015

Matias, G., Faria, P., \& Torres, I. (2014). Lime mortars with ceramic wastes: characterization of components and their influence on the mechanical behaviour. Construction and Building Materials, 73, 523-534.

https://doi.org/10.1016/j.conbuildmat.2014.09.108
Momayez, A., Ehsani, M. R., Ramezaniapour, A. A., \& Rajaie, H. (2005). Comparison of methods for evaluating bond strength between concrete substrate and repair materials. Cement and Concrete Research, 35, 748-757. https://doi.org/10.1016/j.cemconres.2004.05.027

Pincha, T., \& Arnon, C. (2010). Utilization of ceramic waste as fine aggregate within Portland cement and fly ash concretes. Cement and Concrete Composites, 32, 440-449. https://doi.org/10.1016/j.cemconcomp.2010.02.004

Silva, B. A., Ferreira Pinto, A. P., \& Gomes, A. (2015). Natural hydraulic lime versus cement for blended lime mortars for restoration works. Construction and Building Materials, 94, 346-360. https://doi.org/10.1016/j.conbuildmat.2015.06.058

Silva, J., de Brito, J., \& Veiga, R. (2010). Recycled red-clay ceramic construction and demolition waste for mortars production. Journal of Materials in Civil Engineering, 22, 236-244. https://doi.org/10.1061/(ASCE)0899-1561(2010)22:3(236)

Silva, J., de Brito, J., \& Veiga, R. (2009). Incorporation of fine ceramics in mortars. Construction and Building Materials, 23, 556-564. https://doi.org/10.1016/j.conbuildmat.2007.10.014

Tchetgnia, N., Marceau, S., \& Chaussadent, T. (2013). Durability of repairs of reinforced concrete structures with modified mortars by polymers. 31èmes Rencontres de l'AUGC, E.N.S. Cachan, 29 au 31 Mai.

Zimbili, O., Salim, W., \& Ndambuki, M. (2014). A Review on the usage of ceramic wastes in concrete production. International Journal of Civil, Environmental, Structural, Construction and Architectural Engineering. 